\title{
Versatile and Simple Apparatus for X-Ray Diffraction Topography
}

\section{Lindegaard-Andersen, Asger}

\section{Published in:}

Review of Scientific Instruments

Link to article, DOI:

10.1063/1.1719493

Publication date:

1965

Document Version

Publisher's PDF, also known as Version of record

Link back to DTU Orbit

Citation (APA):

Lindegaard-Andersen, A. (1965). Versatile and Simple Apparatus for X-Ray Diffraction Topography. Review of Scientific Instruments, 36(12), 1888-1890. https://doi.org/10.1063/1.1719493

\section{General rights}

Copyright and moral rights for the publications made accessible in the public portal are retained by the authors and/or other copyright owners and it is a condition of accessing publications that users recognise and abide by the legal requirements associated with these rights.

- Users may download and print one copy of any publication from the public portal for the purpose of private study or research.

- You may not further distribute the material or use it for any profit-making activity or commercial gain

- You may freely distribute the URL identifying the publication in the public portal

If you believe that this document breaches copyright please contact us providing details, and we will remove access to the work immediately and investigate your claim 


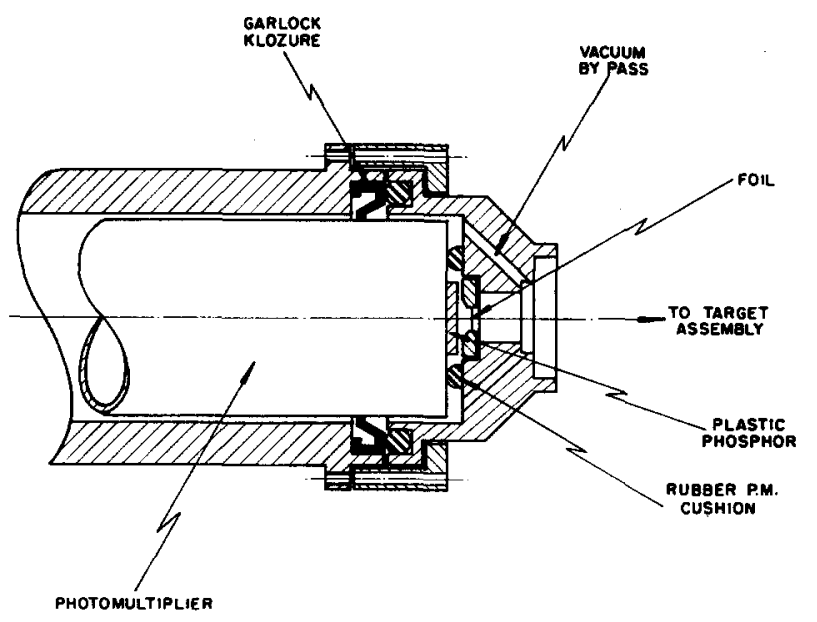

FrG. 1. Photomultiplier assembly.

be an O-ring about the exterior walls of the tube. With the irregular surfaces and variable diameters of photomultipliers this method would require excessive pressures upon the thin walls of the tube. The Garlock Klozure, ${ }^{1}$ primarily intended as a lubricant shaft seal, greatly simplifies the vacuum sealing of the photomultiplier tube assembly.

Garlock model 63X1153 Klozure has been used in conjunction with an RCA 6810A and a Philips 56AVP. Combinations of tubes of either type and a number of $63 X 1153$ Klozures have been tested in the assembly shown in Fig. 1 and the system has always operated at $10^{-7} \mathrm{~mm}$ $\mathrm{Hg}$ without difficulties. Helium leak tests also confirmed the integrity of the seal in all cases.

Tube movement (due to the vacuum) in this assembly is limited by the rubber cushions against the face of the photomultiplier tube. If the full window area is desired, a mechanical clamp at the base of the photomultiplier can be employed.

${ }^{1}$ The Garlock Packing Company of Canada, Ltd., Toronto, Ontario, Canada.

\section{Versatile and Simple Apparatus for X-Ray Diffraction Topography}

\section{A. LINDEgaARd ANDERSEN}

Physics Department, Sect. III, Technical University of Denmark, Lundtofte, Lyngby, Denmark

(Received 28 June 1965; and in final form, 20 August 1965)

$T$ HE potentialities of $x$-ray diffraction topography techniques for mapping dislocations and other defects in single crystals have been widely explored and utilized in recent years. Most use has been made of the transmission Berg-Barrett method, and the adaption of this principle for mapping the volume distribution of dislocations in crystals was mainly due to Lang. ${ }^{1}$ Lang's method utilizes an x-ray point focus, a single slit placed at a relatively large distance from the focus in order to restrict the beam divergence, and a mechanism for the simultaneous scanning of the crystal and the photographic film. Simultaneous diffraction of the $\alpha_{1}$ and $\alpha_{2}$ components can thus easily be avoided and optimal resolution obtained. However, the mechanical construction of the apparatus is rather complex. An alternative method, described by Carlson and Wegener, ${ }^{2}$ utilizes an $\mathrm{x}$-ray line focus and a parallel slit assembly (Soller slits) to restrict the beam divergence. The topograph is recorded by stationary film and crystal. Avoiding simultaneous diffraction of the $\alpha_{1}$ and $\alpha_{2}$ components is thus difficult which results in poorer resolution; however, construction of the apparatus is extremely simple.

A new apparatus is described here which combines the advantages of the above two methods. It utilizes the simple stationary film and crystal technique, but a high resolution has been achieved by introducing oscillating fine Soller slits.

The equipment and experimental arrangement are shown in Fig. 1. The $x$-ray tube is a Philips fine focus tube (focal spot $8 \times 0.4 \mathrm{~mm}$ ). The line focus $A$ is used in a horizontal position; with a viewing angle of $3^{\circ}$ the focus has dimensions $8 \times 0.02 \mathrm{~mm}$. The fine Soller slits $\mathrm{C}$ are made of hardened steel sheets, thickness $0.08 \mathrm{~mm}$, length in the direction of the $x$-ray beam $35 \mathrm{~mm}$, and height $22 \mathrm{~mm}$. The steel sheets are spaced $0.04 \mathrm{~mm}$ apart by means of ribbons of aluminum foil. Thus the incident beam is split up into "parallel" beams each with a horizontal divergence of $2.3 \times 10^{-3} \mathrm{rad}$. In order to smooth out the radiation over the irradiated crystal area the Soller slit assembly is placed in a rocking mechanism (sliding back and forth). Theoretically the rocking amplitude could be as small as the thickness of the steel sheets, but due to unavoidable misalignment and variations in the spacing of the steel sheets it is preferable to make the amplitude somewhat larger, say about $2 \mathrm{~mm}$. The rocking must be at a constant speed in either direction; otherwise the recorded image will be striped. The crystal $D$ is placed on a goniometer head E. The distance between the x-ray focus and the crystal is about $60 \mathrm{~cm}$. The crystal is oriented for reflection with

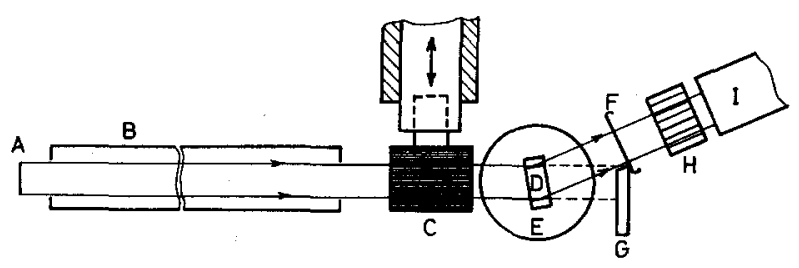

FIG. 1. Schematic of experimental setup projected on the horizontal plane. A-line focus of the $\mathrm{x}$-ray tube; $\mathrm{B}$-collimator tube; $\mathrm{C}$-fine Soller slits mounted in a rocking mechanism; D-crystal; E-goniometer head; $\mathrm{F}-$ photographic film holder; $\mathrm{G}$ - beam stop; $\mathrm{H}-$ coarse Soller slits; and I-Geiger counter. 
the aid of a Geiger counter I connected to a simple counting ratemeter. A coarse Soller slit assembly $\mathrm{H}$ is placed in front of the counter in order to prevent stray radiation from entering the counter. The topograph is recorded on a photographic film placed in a film holder $F$ which is mounted on the beam stop $\mathrm{G}$.

Topographs of crystal areas $8 \times 20 \mathrm{~mm}$ can be obtained both by the transmission Berg-Barrett method and by the anomalous transmission method following Schwuttke's arrangement. ${ }^{3}$ Finally, surface topographs by the back reflection Berg-Barrett method can be obtained with the geometrical arrangement according to Newkirk. ${ }^{4}$

In order to demonstrate the efficiency of the apparatus when used for the Berg-Barrett transmission method, the diffracted energy current versus the angle $\theta$ between the incident central beam (slit axis) and the reflecting planes for the $\overline{2} 20$ reflection of $\mathrm{Mo} \mathrm{K}_{\alpha}$ radiation in silicon is shown in Fig. 2. This curve was obtained with a $0.2 \mathrm{~mm}$ thick slice of a $100 \Omega \mathrm{cm} \mathrm{n}$ type zone floated silicon crystal cut approximately parallel to a $\{211\}$ plane perpendicular to the reflecting planes. The dislocation density of the crystal was around $10^{4} \mathrm{~cm}^{-2}$. The diffracted energy current was measured by stationary fine Soller slits with a simple counting ratemeter. The window of the counter and the spacing of the coarse Soller slits in front of the counter were large enough to insure that the total amount of diffracted energy was recorded. Experiments with other positions of the Soller slits gave identical curves, and experiments with a dislocation free crystal yielded essentially the same shape and angular width of the curve. The total diffracted energy current curve in Fig. 2 has been resolved geometrically in $\alpha_{1}$ and $\alpha_{2}$ components. It is evident that the $\alpha_{2}$ component cannot be totally excluded from a topograph, but it can be suppressed to about $7 \%$ of the $\alpha_{1}$ component by setting the crystal at an angle $\theta$ corresponding to position (a) in Fig. 2. In order to study the effect of the $\alpha_{2}$ component on the optical resolution, topo-

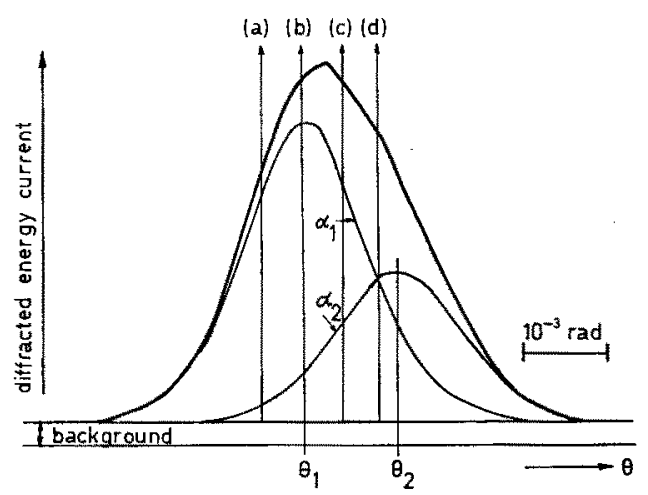

Frg. 2. Experimental diffracted energy current of the 220 reflection of $\mathrm{Mo}_{\alpha}$ radiation in silicon. The total diffracted energy curve has been resolved geometrically in the $\alpha_{1}$ and $\alpha_{2}$ components.

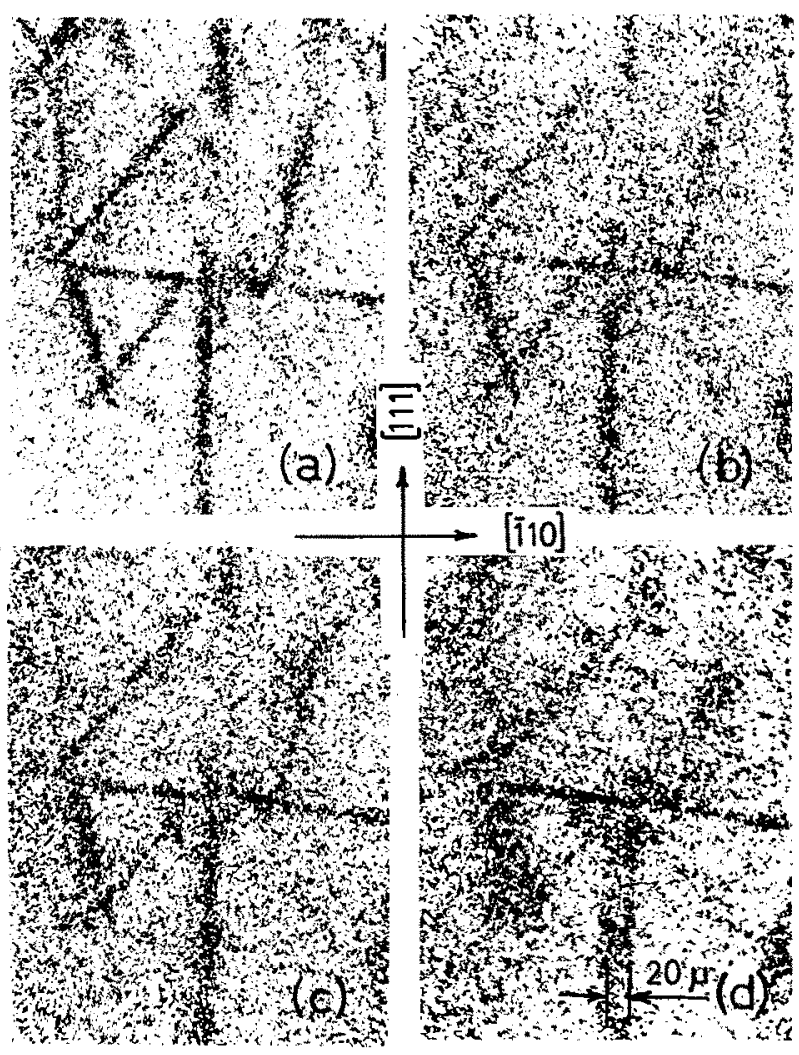

FIG. 3. 220 topographs taken at crystal settings (a), (b), (c), and (d) indicated in Fig. 2. The ratio $\alpha_{2} / \alpha_{1}$ between the contributions of the two $\mathrm{K}_{\alpha}$ components is approximately: (a) 0.07 , (b) 0.15 , (c) 0.42 , and (d) 1.0 . The recording data were unfiltered Mo radiation $50 \mathrm{kV}$, $10 \mathrm{~mA}$, and Ilford Nuclear Research Plate G5, $50 \mu$, exposure time $20 \mathrm{~min}$.

graphs were taken with crystal settings corresponding to the $\theta$ values indicated by (a), (b), (c), and (d) in Fig. 2 . Identical areas of these topographs are shown at a high magnification in Fig. 3. It is evident that increasing contribution of the $\alpha_{2}$ component deteriorates the horizontal resolution (images of dislocations running vertically or diagonally in the picture are widened), whereas the vertical resolution is almost unaffected (image width of horizontal dislocations is unaffected). In Fig. 3(d) the contribution of $\alpha_{2}$ is equal to the contribution of $\alpha_{1}$, which should result in two equally dense images of a vertical dislocation. The two images of the vertical dislocation in Fig. 3(d) are just resolved, the spacing being about $20 \mu$ in accordance with the expected value (the angular difference $\theta_{2}-\theta_{1}$ between the Bragg angles of the $\alpha_{2}$ and $\alpha_{1}$ components times the distance between crystal and film).

Besides the simplicity of the mechanical design the described apparatus has the advantage of yielding a high diffracted energy current. If the photographic film is replaced by an $x$-ray sensitive vidicon tube in a television camera, the apparatus could be used for studying dynamical dislocation behavior in macroscopic volumes of nearly 
perfect crystals. A vidicon tube, which probably is sufficiently $\mathrm{x}$-ray sensitive, has been described by McMaster and Battema. ${ }^{5}$

${ }^{1}$ A. R. Lang, J. Appl. Phys. 29, 597 (1958); and Acta Cryst. 12, 249 (1959).

${ }^{2}$ H. A. Carlson and H. A. R. Wegener, J. Appl. Phys. 32, 125 (1961).

3 G. H. Schwuttke, J. Appl. Phys. 33, 2760 (1962).

4 J. B. Newkirk, Trans. AIME 215, 483 (1959)

5 R. C. McMaster and J. P. Battema, Norelco Reporter 11, 3 (1964)

\section{Microelectrophoresis and Microinjection Assembly for the Chance-Legallais Microfluorimeter}

E. Kohen and V. A. Legallais

Johnson Research Foundation, University of Pennsylvania, Philadelphia, Pennsyluania

(Received 12 July 1965; and in final form, 18 August 1965)

A PERFUSION method $^{1}$ for the microfluorimeter of Chance and Legallais ${ }^{2}$ has allowed the assay of reduced pyridine nucleotides in localized portions of single living cells in a variety of metabolic states. For a study of metabolites which cannot penetrate the cell we have adapted a combined microelectrophoresis ${ }^{3}$ and microinjection ${ }^{4}$ assembly which permits the use at will of either method in conjunction with microfluorimetry.,2

The difficulty in combining micromanipulation with microfluorimetry arose from the incompatibility between the high power short-working-distance darkfield condenser of the microfluorimeter ${ }^{2}$ and the spatial requirements for microinstruments. A solution was found through selection of a Leitz Ultropak system ( $55 \times$ or $22 \times$ ) mounted on an inverted Unitron microscope which provided darkfield illumination, but left the top of the microscope stage free for micromanipulation. ${ }^{5}$ A sliding lamp mount allows illumination from either a tungsten lamp or a mercury arc. The filters in the path of the exciting radiation and the signal-to-noise ratio are as previously reported. ${ }^{1}$

The motion of the main instrument (microelectrode or micropipette) is controlled by a Cailloux (Stoelting $51500-\mathrm{M}$ ) micromanipulator. The reference electrode or the auxiliary instrument for holding the cell by microelastimetry ${ }^{4}$ is moved by a Linetool Company micropostioner model J supplemented with a Brinkman clamp type E. ${ }^{6}$ The microinjector ${ }^{4}$ consists of a Starrett No. 263 or a Brown and Sharpe 1 in. $(2.54 \mathrm{~cm})$ micrometer head driving a tuberculin syringe. The chamber within a bayonet type microinstrument holder (Fig. 1) with inner nylon coating connects the microinjector to the microelectrode which may be used also as a micropipette. ${ }^{3}$ The syringe, connecting polyethylene tubing (Clay-Adams Intramedic Pe60) and microelectrode, is filled with a 0.1 to $1 M$ solution of the compound to be introduced within the cell.

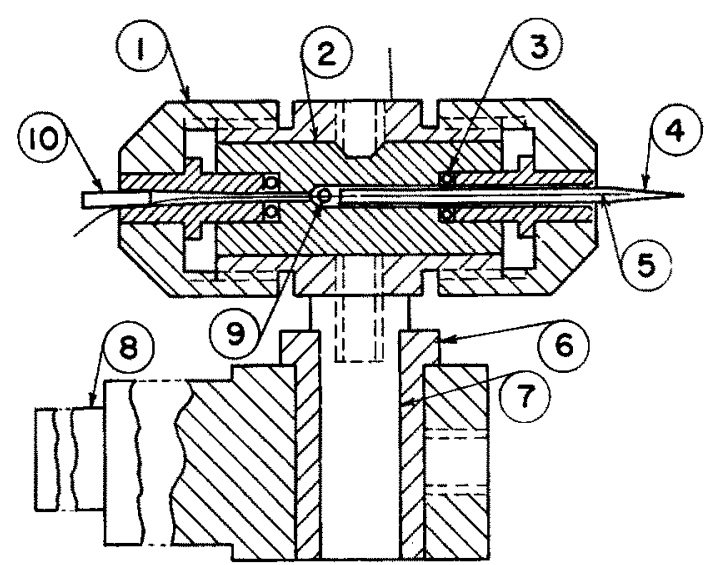

FIG. 1. Cross section of microelectrode holder: (1)-knurled nut, (2)-nylon insulator, (3)-O-ring seal, (1)-microelectrode, (1)-platinum wire, (ㄷ) nylon insulator, (0)-metal shank, (8)-metal shank to connect to manipulator (Cailloux or Brinkman clamp type E), (๑-inlet port; and (10-metal tapered pin, removable. The removable tapered pin is used as a distortion free connection of platinum wire to frame; it permits fast easy adjustment and replacement of a straight segment of platinum wire.

The diameter of the microelectrode tip is about 1 to $4 \mu$ and a $0.2 \mathrm{~mm}$ platinum wire is inserted into the glass capillary as far as 5 to $10 \mathrm{~mm}$ from the tip. The reference electrode has a similar platinum wire, but it is filled with $1 M \mathrm{KCl}$ and its tip diameter is $50 \mu$ or over. The current flows from the brass surface of the holder to a stainless steel tapered pin which is in contact with the platinum. For microelectrophoresis of metabolites (mainly anions) the microelectrode is connected to the negative pole of a 15 cell battery with voltage range from 3 to $22.5 \mathrm{~V}$ (Burgess 5156). The voltage for each experiment is selected in accordance with the desired microelectrode tip current measured by a recording microammeter (Heath EUW20A). Microelectrophoresis experiments with fluorescent tracers (reduced diphosphopyridine nucleotide) have shown that a current of 5 to $10 \mathrm{sec}$ duration will generally suffice for introducing a more than adequate concentration of the compound for metabolic requirements. No precautions were taken to coat the platinum electrode, since no electrolytic accumulation of bubbles was observed during the relatively brief time course of microelectrophoresis, and coating would have increased the resistance. Each time before starting the current for ejection of compounds into a new cell, gentle pressure is applied to bring the solution to the microelectrode tip and to replace the fluid around the electrode.

Reduced diphosphopyridine nucleotide and glucose-6phosphate were introduced microelectrophoretically into giant tissue culture ascites cells with tip currents of $1.5 \times 10^{-7}$ and $6 \times 10^{-8} \mathrm{~A} / \mu^{2}$ and the intracellular concentrations reached were in the range of $40 \mathrm{mM}$ and 8-10 $\mathrm{mM}$, respectively. Thus the modifications introduced in 